\title{
Clinical Characteristics and Survival of Patients with Pulmonary Hypertension: A 40-Month Mean Follow-Up
}

\author{
López Reyes R, Nauffal D*, Garcia Ortega A, Menéndez MA, Fandos MJ and Ansotegui E
}

Department of Pneumology, University Hospital La Fe, Avda Bulevar Sur, s/n 46026 Valencia, Spain

"Corresponding author: Dra Dolores Nauffal Manzur, Hospital Universitari i Politècnic La Fe, Avda Bulevar Sur SN, 46026 Valencia, Spain, Tel: +34961245794; Fax: +34961245794; E-mail: dneuffal@separ.es

Received date: Dec 18, 2014, Accepted date: Jan 26, 2015, Published date: Jan 29, 2015

Copyright: @ 2015 Reyes LR, et al. This is an open-access article distributed under the terms of the Creative Commons Attribution License, which permits unrestricted use, distribution, and reproduction in any medium, provided the original author and source are credited.

\begin{abstract}
Introduction: The aim of our study was to describe the characteristics and clinical outcomes of pulmonary hypertension $(\mathrm{PH})$ patients who underwent their follow-up at a single centre.

Methods: We included patients who fulfilled the criteria for the diagnosis of $\mathrm{PH}$ by right heart catheterisation. A detailed clinical history and complete physical examination were recorded for each patient. Demographic data, laboratory testing, hemodynamic values and treatment records were also collected. A 6-minute walk test was used to evaluate exercise capacity. Survival analysis was performed using the Kaplan-Meier method, and a log-rank test was used to compare survival curves among groups. A multivariate Cox's proportional hazards model was used in order to identify independent predictors of mortality in the overall $\mathrm{PH}$ population.
\end{abstract}

Results: A total of 93 patients (64 women and 29 men) were studied. The patients were distributed across the groups as follows: $50.5 \%$ in group $1,20.4 \%$ in group $2,9.7 \%$ in group 3, $14 \%$ in group 4 and $5.4 \%$ in group 5 . The most common type of $\mathrm{PH}$ in our population was portopulmonary hypertension followed by $\mathrm{PH}$ associated with leftheart disease, and idiopathic and chronic thromboembolic disease. Nineteen deaths, constituting $20.5 \%$ of the sample population, were reported. The Kaplan-Meier estimates of the 1-, 2-, and 3-year survival rates were $91 \%$, $89 \%$, and $85 \%$, respectively. There were no statistically significant differences in survival among the groups $(p=0.18)$. A multivariate analysis revealed that the cardiac index $(\mathrm{Cl})$ was an independent predictor of death.

Conclusions: The survival rates of $\mathrm{PH}$ patients are higher than previously reported. In our study, the largest number of deaths occurred in groups 1 and 2, and $\mathrm{Cl}$ was found to be an independent predictor of mortality.

Keywords: Pulmonary hypertension; Pulmonary arterial hypertension; Survival; Prognosis factors

\section{Introduction}

Pulmonary hypertension $(\mathrm{PH})$ is a rare and severe condition that involves numerous aetiologies and several mechanisms. It includes a heterogeneous group of disorders and is defined as a mean pulmonary artery pressure of $25 \mathrm{mmHg}$ or greater during cardiac catheterisation. According to Nice, there are five different categories of $\mathrm{PH}$ based on pathophysiological characteristics, expected responses to treatment and prognosis [1].

Pulmonary arterial hypertension (PAH) is a conspicuous state characterised by a pre-capillary $\mathrm{PH}$ (pulmonary capillary wedge pressure (Ppcw) $<15 \mathrm{mmHg}$ ). PAH (group 1) can be idiopathic (IPAH), heritable, induced by drug or toxin exposure, or develop as a consequence of many disorders, such as connective tissue diseases, HIV infection, congenital heart diseases or portal hypertension. Group $2 \mathrm{PH}$ is commonly due to left-heart disease (LHD) and is associated with a chronically elevated Ppcw. The predominant cause of $\mathrm{PH}$ in Group 3 is alveolar hypoxia due to chronic lung disease. Group 4 is characterised by chronic thromboembolic pulmonary hypertension $(\mathrm{CTEPH})$, and group 5 includes $\mathrm{PH}$ patients with unclear and/or multifactorial mechanisms [1].
PAH is characterised by pulmonary vasoconstriction, in situ thrombosis, and altered endothelial function, all of which lead to a sustained increase in pulmonary vascular resistance. Common PAH symptoms include breathlessness, loss of exercise capacity and death due to an elevated pulmonary artery pressure and subsequent rightheart failure. Right-heart catheterisation is mandatory for the safe diagnosis of PAH patients [1-3].

Based on concurrent conditions, conventional treatment includes oral anticoagulants, oxygen supplementation, diuretics, digoxin, and vasodilators. Calcium antagonists have been shown to be efficacious in a very specific PAH subpopulation of acute testing responders. Acute vasodilator responders represent approximately $10 \%$ of IPAH or anorexigen-associated $\mathrm{PAH}$; however, acute vasodilator responders are uncommon in cases of hereditable disease [1].

The median survival rate for $\mathrm{PH}$ patients who do not receive treatment is 2.8 years. Survival rates of $68 \%, 48 \%$, and $34 \%$ at 1,3 , and 5 years, respectively, have been reported by D'Alonzo et al. [4]. Intervention using specific therapies can modify the course of this fatal disease, and recently, more than 30 randomised controlled trials (RCTs) have been carried out to improve the survival and quality of life of $\mathrm{PH}$ patients. For the vast majority of IPAH patients, targeted treatments include use of prostacyclin derivatives, endothelin receptor antagonists, and/or phosphodiesterase type 5 inhibitors [1,5]. Several observational studies have demonstrated that these current $\mathrm{PAH}$ 
specific therapies improve long-term survival [6-9]. Recently, large registries in France, Scotland, the USA and Spain have further characterised $\mathrm{PH}$ [10-13]. Furthermore, these national registries have assessed the survival rates in patients receiving these current treatments. A report on the French registry estimated the survival rates at 1,2 , and 3 years to be $85.7 \%, 69.6 \%$, and $54.9 \%$, respectively [14,15]. The REVEAL registry showed that the 1-, 3-, and 5-year survival rates were $85 \%, 68 \%$, and $57 \%$, respectively [15]. Similar data were recently reported for the Spanish registry (REHAP) [13]. Use of thromboendarterectomies for patients with chronic thromboembolic pulmonary hypertension (CTPH) has been successfully implemented and constitutes the only curative option for CTPH.

Despite these achievements, $\mathrm{PH}$ continues to be a life-threatening condition, and there is often a delay from the onset of symptoms to diagnosis. Therefore, it is essential to identify novel prognosis factors that can be used to improve the management of $\mathrm{PH}$.

The aim of our study was to characterise a cohort of $\mathrm{PH}$ patients based on their survival rates and identify adverse prognostic factors present at diagnosis.

\section{Material and Methods}

\section{Study population}

We evaluated all patients diagnosed with $\mathrm{PH}$ at the University Hospital La Fe from January 2002 to November 2012. An informed consent was obtained from all study participants. Patients diagnosed in the period 2002-2007 were entered retrospectively. Patients diagnosed between 2008 and 2012 were prospectively added to the study. All patients underwent a follow-up visit during the study.

The diagnosis of $\mathrm{PH}$ required a right heart catheterisation with a mean pulmonary artery pressure greater than $25 \mathrm{mmHg}$, and each patient was assigned to one of five groups based on their symptoms.

\section{Data collection}

Baseline data collected from patient records included demographic information (age, gender, height and body weight), clinical diagnosis, comorbidities (i.e., connective tissue diseases, liver diseases, chronic renal failure and thyroid dysfunction), World Health Organization (WHO) functional class (FC), 6-Minute Walk Distance (6MWD), echocardiographic parameters, haemodynamics assessed by right heart catheterisation, and treatment course. The hemodynamic parameters included mean pulmonary artery pressure, cardiac output, cardiac index, pulmonary vascular resistance, and mixed venous oxygen saturation. Standard pulmonary vasoreactivity was determined according to ERS guidelines. A response to the acute vasodilator test was defined as a decrease in mean pulmonary arterial pressure by at least $10 \mathrm{mmHg}$ to an absolute level of less than $40 \mathrm{mmHg}$ without a reduction in cardiac output [1].

The same process was completed for patients who entered the study prospectively. In all cases, clinical status, exercise capacity and echocardiography were evaluated at a 6 month follow-up.

The primary endpoint was death. The date and cause of death were verified by medical records. Survival was estimated from the date of diagnosis to death or the last date of contact.

\section{Statistical analysis}

Continuous variables are presented as the mean \pm standard deviation or median. Differences between two groups were assessed using an independent sample t-test or nonparametric test (MannWhitney test). For multiple comparisons of quantitative data, a oneway analysis of variance or Kruskal-Wallis test was used. Categorical variables were described by frequencies and percentages. Comparisons between these groups were made using chi-square or Fisher exact tests.

Survival analysis was performed using the Kaplan-Meier method, and differences between the curves were analysed using the log-rank test. A univariate Cox proportional hazards analysis was used to examine the relationship between survival and the demographics, biomarkers, haemodynamics, and functional variables that were collected at diagnosis. All variables with a $\mathrm{P}<0.05$ were tested in a backwards stepwise multivariable Cox proportional hazards analysis. These data are expressed as a hazard's ratio (HR) with $95 \%$ confidence interval (CI). The two-sided significance level was set at 0.05 .

Statistical analyses were performed using SPSS 20.0 software.

\section{Results}

\section{Patient characteristics}

Ninety-three patients were included in this study. A total of 68 (73.1\%) patients were diagnosed during the recruitment period and enrolled. The remaining participants were diagnosed with $\mathrm{PH}$ before the start of the study. Therefore, there were 68 incident cases and 25 prevalent cases. The mean follow-up was 40.4 months. The baseline characteristics for the study participants are listed in Table 1. The median age was $58.8 \pm 17.2$ years, and the female/male ratio was $68 / 32 \%$. The distribution of WHO group diagnostic classifications at enrolment are shown in Figure 1. The most common type of $\mathrm{PH}$ in our population was portopulmonary hypertension, followed by $\mathrm{PH}$ associated with left-heart disease, IPAH and chronic thromboembolic $\mathrm{PAH}$. The idiopathic form of PAH represented $16.1 \%$ of the total cohort.

\begin{tabular}{|l|l|}
\hline Subjects $\mathrm{n}$ & 93 \\
\hline Age, $\mathrm{yr}$ & $58.8 \pm 17.2$ \\
\hline Gender (M/F) & $29 / 64$ \\
\hline BMI (Kg/m2) & $28.2 \pm 5.7$ \\
\hline Symptoms (n= 93) & \\
\hline Peripheral oedema & $25.8 \%(24)$ \\
\hline Syncope & $14 \%(13)$ \\
\hline Chest pain & $12.9 \%(12)$ \\
\hline WHO FC (\%) & \\
\hline I-II & 38.7 \\
\hline III-IV & 61.3 \\
\hline Group of PH (\%) & \\
\hline I & 50.5 \\
\hline II & 20.4 \\
\hline
\end{tabular}


Citation: Reyes LR, Nauffal D, Ortega GA, Menéndez MA, Fandos MJ, et al. (2015) Clinical Characteristics and Survival of Patients with

Page 3 of 7

\begin{tabular}{|l|l|}
\hline III & 9.7 \\
\hline IV & 14 \\
\hline V & 5.4 \\
\hline Pulmonary function & \\
\hline FVC (\%) & $90.3 \pm 21.8$ \\
\hline FEV1 (\%) & $82.2 \pm 24.2$ \\
\hline TLC $(\%)$ & $92.4 \pm 18.3$ \\
\hline DLCO (\%) & $63.4 \pm 20.5$ \\
\hline DLCO/VA & $76.72 \pm 20.6$ \\
\hline PO2 & $69.3 \pm 13.5$ \\
\hline PCO2 & $39.2 \pm 9.3$ \\
\hline 6MWD & $387.8 \pm 124.8$ \\
\hline proBNP & $2404.5 \pm 4103.3$ \\
\hline Haemodynamics & \\
\hline sPAP, mmHg & $64.2 \pm 21.3$ \\
\hline dPAP, mmHg & $27.8 \pm 9.7$ \\
\hline mPAP, mmHg & $41.86 \pm 13.3$ \\
\hline PCWP, mmHg & $17.3 \pm 7.2$ \\
\hline TPG, mmHg & $23.2 \pm 11.9$ \\
\hline SVO2, \% & $65.85 \pm 9.2$ \\
\hline CO, L.min-1 & $4.8 \pm 2.2$ \\
\hline Cl, L. Min ${ }^{-1}$ & $2.7 \pm 1.3$ \\
\hline PVR, din.seg.cm 5 & $432.4 \pm 297.6$ \\
\hline
\end{tabular}

${ }^{\star}$ Values are shown as the mean \pm SD. Abbreviations: BMI (body mass index), WHO (World Health Organization), FC (functional class), FVC (forced volume capacity), FEV1 (forced expiratory volume in 1 second), TLC (total lung capacity), DLCO (diffusing capacity of carbon monoxide), DLCO/VA (DLCO corrected for alveolar volume), 6MWD (6-min walk distance), proBNP (brain natriuretic peptide), sPAP (systolic pulmonary artery pressure), dPAP (diastolic pulmonary artery pressure), mPAP (mean pulmonary artery pressure), mPAP (mean pulmonary artery pressure), PCWP (pulmonary capillary wedge pressure), TGP (transpulmonary gradient), $\mathrm{SvO}_{2}$ (mixed venous oxygen saturation), $\mathrm{CO}$ (cardiac output), CI (cardiac index), PVR (pulmonary vascular resistance).

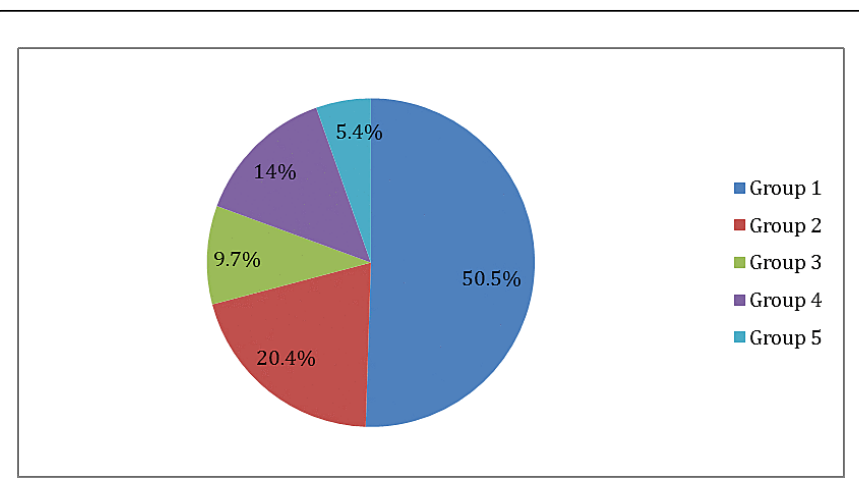

Figure 1: World Health Organization (WHO) groups 1 to 5 for pulmonary hypertension classification.

The median duration of symptoms until diagnosis was 18 months regardless of gender. Dyspnoea was the most common symptom at the time of diagnosis $(91.4 \%)$. Other less common symptoms included peripheral oedema (25.8\%), syncope (14\%) and chest pain (12.9\%).

\section{PH subgroups}

The patient characteristics for all types of PAH are shown in table 2. We included the most prevalent forms of $\mathrm{PAH}$ in our population. Among patients with IPAH, connective tissue diseases (CTDs) or portopulmonary hypertension were the most frequent diagnosis.

Table 1: Demographics and clinical characteristics at the time of diagnosis $^{*}$

\begin{tabular}{|c|c|c|c|c|c|}
\hline & IPAH & CTD & PoPH & CTEPH & LHD \\
\hline Subjects $\mathrm{n}$ & 15 & 8 & 18 & 14 & 19 \\
\hline Age (yrs) & $48.3 \pm 17.4$ & $53.3 \pm 20.1$ & $48.9 \pm 8.3$ & 68.711 .2 & $67.8 \pm 9.3$ \\
\hline Gender (M/F) & $2 / 13$ & $0 / 9$ & $11 / 7$ & $6 / 8$ & $5 / 14$ \\
\hline IMC $\left(\mathrm{Kg} / \mathrm{m}^{2}\right)$ & $25.8 \pm 4,7$ & $22.8 \pm 2.5$ & $30.3 \pm 5.1$ & $28.5 \pm 5.2$ & $30.4 \pm 4.6$ \\
\hline FVC (\%) & $91.9 \pm 18.1$ & $76.3 \pm 32.7$ & $104.2 \pm 13.3$ & $92.1 \pm 21.4$ & $87.1 \pm 22$ \\
\hline FEV1(\%) & $83.8 \pm 23.7$ & $73.9 \pm 24.9$ & $92.58 \pm 13.6$ & $83.4 \pm 26.2$ & $80.5 \pm 23.5$ \\
\hline DLCOc/VA & $73.6 \pm 15.1$ & $66.4 \pm 13.3$ & $65.7 \pm 15.7$ & $85.9 \pm 28.5$ & $89.1 \pm 16.6$ \\
\hline \multicolumn{6}{|l|}{ WHO FC (\%) } \\
\hline $\mid-I I$ & 26.7 & 37.5 & 61.1 & 21.4 & 31.3 \\
\hline III-IV & 73.3 & 62.5 & 38.9 & 78.5 & 68.7 \\
\hline
\end{tabular}


Citation: Reyes LR, Nauffal D, Ortega GA, Menéndez MA, Fandos MJ, et al. (2015) Clinical Characteristics and Survival of Patients with

\begin{tabular}{|l|l|l|l|l|l|}
\hline 6MWT, $\mathrm{m}$ & $401 \pm 141.6$ & $316.7 \pm 81.1$ & $462.4 \pm 110.2$ & $302.8 \pm 128.4$ & $330.2 \pm 93$ \\
\hline proBNP & $2401.1 \pm 3025.4$ & $1246.1 \pm 1450.5$ & $695.1 \pm 1216.9$ & $2209.4 \pm 3088.0$ & $2523.1 \pm 1777.8$ \\
\hline Echocardiography sPAP & $81.6 \pm 82.7$ & $67.6 \pm 33.8$ & $75.2 \pm 25.2$ & $70.7 \pm 14$ & $66.3 \pm 15.5$ \\
\hline Haemodynamics & \multicolumn{5}{|l|}{} \\
\hline sPAP $(\mathrm{mmHg})$ & $71 \pm 22.6$ & $61 \pm 21.7$ & $70.7 \pm 21.7$ & $69.5 \pm 19.6$ & $59.7 \pm 16.2$ \\
\hline dPAP $(\mathrm{mmHg})$ & $34.7 \pm 12.5$ & $29.3 \pm 8.5$ & $30.6 \pm 10.17$ & $25.9 \pm 8.4$ & $23.5 \pm 4.2$ \\
\hline mPAP $(\mathrm{mmHg})$ & $47.6 \pm 15.2$ & $40.8 \pm 14.5$ & $46.7 \pm 14.5$ & $43.5 \pm 12.7$ & $39 \pm 9.4$ \\
\hline PCWP, mmHg & $10.4 \pm 3.8$ & $12.4 \pm 3.2$ & $19.7 \pm 6.7$ & $14.5 \pm 7.3$ & $21.2 \pm 8.4$ \\
\hline TPG, mmHg & $30.3 \pm 14.2$ & $28.6 \pm 13.2$ & $26.1 \pm 14.9$ & $23.6 \pm 11.5$ & $17.2 \pm 6.9$ \\
\hline DPD, mmHg & $19.2 \pm 10.8$ & $14 \pm 8.4$ & $10.8 \pm 11.1$ & $12.4 \pm 9.2$ & $4.7 \pm 4.9$ \\
\hline CO $(I . m i n-1)$ & $4.8 \pm 1.8$ & $3.1 \pm 2.5$ & $5.8 \pm 2.4$ & $4.1 \pm 1.5$ & $4.6 \pm 1.9$ \\
\hline Cl (I. min-1.m $\left.{ }^{2}\right)$ & $2.6 \pm 1.2$ & $1.9 \pm 1.9$ & $3.1 \pm 1.3$ & $2.2 \pm 0.8$ & $2.5 \pm 1.1$ \\
\hline PVR (din.seg.cm-5) & $656.3 \pm 416.3$ & $418.151 .5 \pm 151.1$ & $425.1 \pm 323.1$ & $515.4 \pm 3.1$ & $287.6 \pm 141.6$ \\
\hline
\end{tabular}

Table 2: Clinical and haemodynamic data at diagnosis for each PAH subgroup and CTEPH

Values are shown as the mean \pm SD. Abbreviations: IPAH (idiopathic PAH), CTD (connective tissue disease), PoPH (portopulmonary hypertension), LHD (left heart disease), WHO (World Health Organization), FC (functional class), 6MWT (6-minute walking test), sPAP (systolic pulmonary artery pressure), dPAP (diastolic pulmonary artery pressure), mPAP (mean pulmonary artery pressure), PCWP, mmHg (pulmonary capillary wedge pressure), TGP (transpulmonary gradient), DPD (diastolic pressure difference), CO (cardiac output), CI (cardiac index), PVR (pulmonary vascular resistance).

\section{Functional class}

Most patients had moderate symptoms at the time of diagnosis with $30.1 \%$ and $51.6 \%$ in functional class (FC) II and III, respectively.

The patient's baseline exercise capacity was evaluated using a 6minute walk test in 39 patients. The mean 6-minute walk distance $(6 \mathrm{MWD})$ at the time of diagnosis was $387.8 \pm 124.8 \mathrm{~m}$. There was a clear correlation between 6MWT and FC (r: 0.5). PVR showed a mild correlation with FC.

\section{Pulmonary function and echocardiography}

Patients showed preserved spirometry and lung volume with a moderate reduction in \% DLCO $(63.4 \pm 20.5)$.

The mean systolic pulmonary arterial pressure measured by echocardiography was $70.87 \pm 21.32 \mathrm{mmHg}$. Most patients exhibited right ventricular dilatation at diagnosis; however, only a small percentage of patients had an abnormal interventricular septal motion $(21.2 \%)$ or pericardial effusion (10.6\%).

\section{Haemodynamics}

Patients had moderate pulmonary hypertension with an increase in mean pulmonary artery pressure (41. $8 \pm 13.3 \mathrm{mmHg}$ ), high pulmonary vascular resistance, and slightly reduced cardiac index. The results of the RHC used to enrol patients are shown in Table 1. There were significant differences $(\mathrm{p}<0.05)$ in $\mathrm{mPAP}, \mathrm{PVR}$ and Pcwp among $\mathrm{PH}$ groups. In our population, only $\mathrm{Pcwp}$ showed a significant difference in the most common PH groups.

\section{Treatment}

Fifteen patients (16.1\%) received conventional therapy only, these belonged to group 2 of $\mathrm{PH}$. Fourteen patients (15.1\%) were treated with digoxin, forty-seven patients $(50.5 \%)$ were treated with diuretics and fifty-one patients (54.8\%) received acenocumarol at baseline. Anticoagulants were used in all patients with CTEPH and most idiopathic forms and associated with left heart disease. A total of $26.9 \%$ of patients had a positive vasoreactivity test. Calcium channel blockers were given to $9.7 \%$ of patients. All patients in group 1 and 4 were treated with specific therapy. Bosentan alone and sildenafil alone were the most commonly used initial treatments in these groups. A total of 9 patients (11.5\%) were treated with a prostacyclin analogue, including subcutaneous treprostinil in one patient, inhaled iloprost in 4 patients and intravenous epoprostenol in 4 patients. Combined therapy was used at the time of diagnosis in $6.6 \%$ of patients. The most common combination therapy included bosentan and sildenafil. The therapeutic options are outlined in Table 3.

\begin{tabular}{|l|l|}
\hline Oral anticoagulation & $51(54.8)$ \\
\hline Calcium channel blockers & $9(9.7 \%)$ \\
\hline PDE-5 I & $24(25.8 \%)$ \\
\hline ERA & $30(32.3 \%)$ \\
\hline Prostanoids & $9(9.7 \%)$ \\
\hline Combination therapy & $6(6.6 \%)$ \\
\hline
\end{tabular}

Table 3: Therapeutic options at time of diagnosis 
Citation: Reyes LR, Nauffal D, Ortega GA, Menéndez MA, Fandos MJ, et al. (2015) Clinical Characteristics and Survival of Patients with

Page 5 of 7

ERA $=$ Endothelin receptor antagonist, PDE-5 I= Phosphodiesterase type-5 inhibitor

In group 2, 5 patients $(26.3 \%)$ presented combined post-capillary and pre-capillary $\mathrm{PH}$ and they received specific therapies (sildenafil was the drug more used), despite the lack of evidence to support the use of these drugs in this patients. No specific vasodilators were used in group 3.

No patients in group 4 were considered operable due to their medical conditions, all of them received medical treatment most with bosentan.

\section{Survival}

During a median follow-up period of 40.4 months (1-168), 19 patients died of causes related to $\mathrm{PH}$. A total of 11 deaths were from the previously diagnosed group and eight deaths were from the newly diagnosed group. In group 1 died 14 patients (78.8\%), 4 patients were idiopathic forms, 3 patients were associated with connective tissue disease (scleroderma), 6 patients were portopulmonary hypertension and 1 patient with congenital heart disease. The rest of deaths occurred in group 2 (3 patients with diastolic dysfunction), in group 3 (1 COPD patient) and group 4 . At the time of death most patients were on combination therapy and 7 patients (36\%) were on monotherapy with oral drugs only. Nearly half of patients (42.1\%) was being treated with prostanoids.

For the entire cohort, the observed survival rate at 1,2 , and 3 years was $91 \%, 89 \%$, and $85 \%$, respectively (Figure 2). There were no statistically significant differences between these groups $(p=0.18)$.

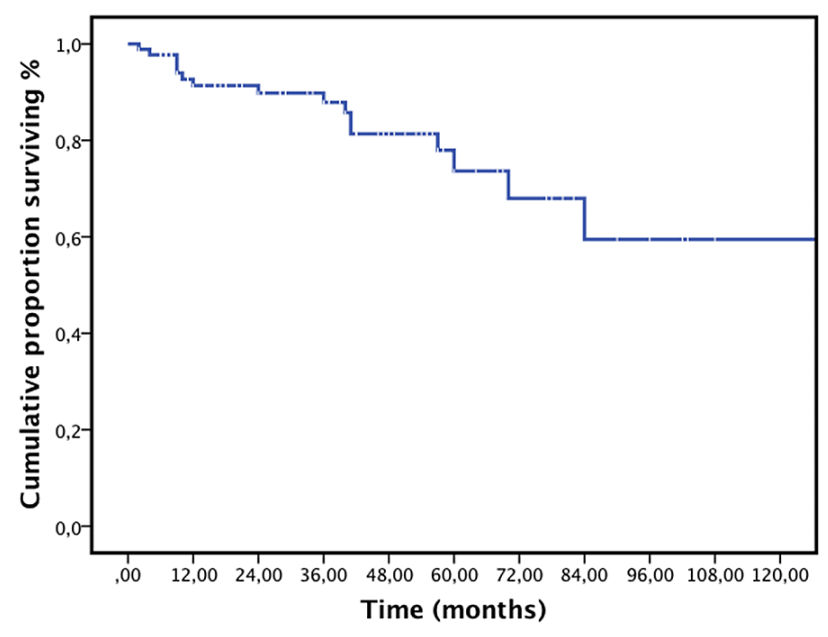

Figure 2: Kaplan Meier survival curve.

Kaplan-Meier survival curves based on multiple aetiologies are shown in Figure 3.

\section{Baseline predictors of survival}

A univariate analysis showed that age, female sex, BNP, PVR, cardiac index and mPAP were associated with an increased risk of death. However, reduced exercise capacity and \% predicted carbon monoxide diffusing capacity were not associated with increased mortality. Among the subtypes of $\mathrm{PAH}$, portal hypertension was related to a high mortality.

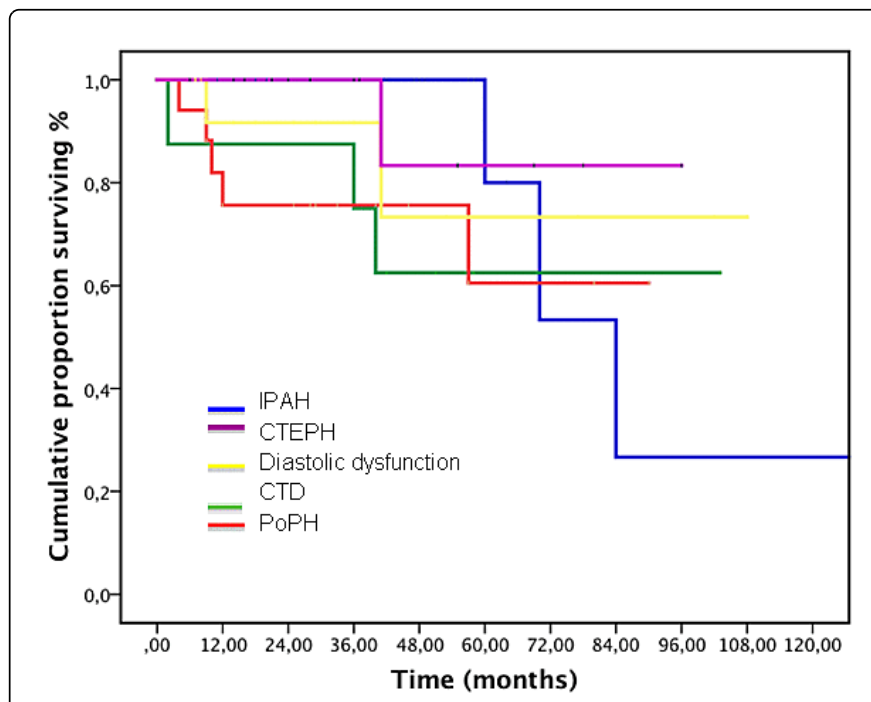

Figure 3: Kaplan Meier survival curves according to aetiology.

IPAH: idiopathic pulmonary arterial hypertension; CTEPH: chronic thromboembolic pulmonary hypertension; CTD: connective tissue disease; PoPH: portopulmonary hypertension.

A multivariable Cox proportional hazards regression analysis revealed that a lower cardiac index was independently associated with an increased risk of death (Table 4).

\begin{tabular}{|l|l|l|}
\hline & HR $(95 \% \mathrm{Cl})$ & $\mathrm{p}$ value \\
\hline mPAP & $1.1(0.9-1.1)$ & 0.09 \\
\hline $\mathrm{Cl}$ & $2.1(1.1-3.9)$ & 0.04 \\
\hline Female & $12.9(0.9-171)$ & 0.05 \\
\hline Age & $1.1(0.9-1.1)$ & 0.1 \\
\hline
\end{tabular}

Table 4: Multivariate predictors of death in Cox`s proportional hazards analysis.

HR: hazard ratio, CI: Concordance interval, mPAP: mean pulmonary artery pressure, CI: cardiac index.

\section{Discussion}

This report describes the clinical characteristics and survival of PH patients based on follow-ups at single centre.

The natural progression of PAH was first described in a pioneer national registry conducted in the United States in the early 1980s that tracked patients with "primary" pulmonary hypertension for up to five years. Recently, several registries have highlighted current epidemiological data, survival rates, and modern treatments. These studies mainly included PAH patients assigned to groups I and IV.

To our knowledge, we are the first to report on patients from all $\mathrm{PH}$ groups. In the present study, the majority of patients belonged to groups 1,2 and 4, which are defined by the presence of 
portopulmonary hypertension, $\mathrm{PH}$ due to left-heart disease (diastolic dysfunction), idiopathic $\mathrm{PAH}$ and chronic thromboembolic $\mathrm{PH}$.

According to recent registries, we found that $\mathrm{PH}$ and $\mathrm{PAH}$ can develop at any age. In our study, the majority of patients were between the 5th and 6th decade of life at the time of diagnosis. This finding is similar to a previous study by Humbert [10]. In our patient cohort, the female to male sex ratio was 2.2:1, confirming the female predominance in most $\mathrm{PH}$ groups. Only group 4 did not show a differences between genders.

There was a mean diagnosis delay of 18 months, which is shorter than the delay reported in the French and REHAP registries (27 and 26 months, respectively) and longer than the delay from the REVEAL registry (12 months). This discrepancy constitutes a significant problem and indicates that an accurate and rapid diagnosis is necessary.

The clinical features of our patients were similar to other studies in that dyspnoea was the most common symptom found in $\mathrm{PH}$ patients.

Most of the patients were diagnosed as group 1, and the most frequent cases were $\mathrm{PH}, \mathrm{IPAH}$, and $\mathrm{PAH}$-associated CTD. These results are in agreement with other registries. In addition, our PAH patients were predominantly women of middle age with a moderate functional class at diagnosis. These characteristics can be partially explained because many of our patients were referred from hepatology or rheumatology after screening revealed signs of $\mathrm{PH}$.

$\mathrm{PH}$ due to left-heart disease (group 2) was the second most common cause of $\mathrm{PH}$ in our study population. It was caused by left ventricular (LV) systolic or diastolic dysfunction or by valvular disease (predominantly mitral valve disorders). This subgroup of patients with diastolic heart failure were older than those of group 1, and their associated comorbidities included obesity, systemic arterial hypertension, diabetes mellitus, atrial fibrillation, and coronary artery disease. Eighty percent (80\%) of our PH-LHD patients exhibited an elevated TPG > $15 \mathrm{mmHg}$, PCWP $>15 \mathrm{mmHg}$, and PVR $>3 \mathrm{Wood}$ units, suggesting a mixed pattern of pre-capillary $\mathrm{PH}$ with diastolic dysfunction.

In the present study, $\mathrm{PH}$ due to lung diseases and or hypoxia represented a minority of patients; however, this could be due to a misdiagnosis because it is very difficult to detect $\mathrm{PH}$ in diseases such as COPD or OSAS. Furthermore, the prevalence of $\mathrm{PH}$ in these COPD or OSAS patients is not well known.

CTEPH patients represented the third most common group in our study. These patients had the oldest mean age when compared with the rest of the patient cohort. Between 3.8 and 5\% of patients with acute pulmonary embolism developed CTEPH due to different mechanisms; however, the most common is a persistent thrombotic occlusion [16-18]. Our results are in agreement with these previously reported studies.

Group 5 patients include a number of miscellaneous conditions, such as hematologic, systemic and metabolic disorders. In the present study, this group included patients with end-stage renal disease. The prevalence of $\mathrm{PH}$ in this population is estimated up to $40 \%$ by echocardiogram. Several mechanisms are implicated in this disease, including high cardiac output, fluid overload and systolic or diastolic left-heart dysfunction [19].

The majority of patients were at functional class III at diagnosis. These findings are in agreement with previously published data
[10-13]. No significant abnormalities in pulmonary functional tests were recorded. We found that the mean exercise capacity during the 6minute walking test was $387.8 \mathrm{~m}$, and this parameter significantly correlated with the FC.

Our echocardiography study showed a high proportion of patients with a right ventricular enlargement at baseline. These data were not collected in the majority of previous studies; thus, we can not compare our results. A small number of patients had a small pericardial effusion. Similar to previous reports, these patients had a shorter survival time when compared with patients without this type of effusion [20].

All patients underwent RHC and a pulmonary vasodilator or vasoreactivity test as suggested by the currently accepted management algorithm. The majority of patients had a negative response to the vasoreactivity test, in concordance with previous studies. The baseline hemodynamic data in our study indicated that patients with IPAH had higher $\mathrm{mPAP}$ and PVR values than patients with other forms of $\mathrm{PH}$; however, these differences were not significant.

The majority of patients were initially treated with a single oral vasodilator drug. Only a small proportion of patients required combined therapy based on their FC and haemodynamics. Patients in FC-IV received intravenous prostacyclin or an analogue. The management of patients in our study is in concordance with that of most previous reports.

The one-, two- and three-year survival rates for the study cohort was significantly higher than those reported in the National registry study from the USA, with the exception of a similar rate in cases of portopulmonary hypertension [4]. Groups 1 and 2 were associated with a poor prognosis in the present study. However, our results show a higher global survival rate that a previous study by D'Alonzo [4]. An improved diagnosis with better suited treatment options may be the cause of the increased survival rate. The survival of our patients is slightly higher than reported by Humbert et al; however, this prior study only included PAH (group 1) patients, which typically have the worst prognosis [15].

In the present study, the only significant risk factor associated with an increased mortality is a low CI at baseline. Unlike Humbert et al, we did not find that sex, right ventricular dysfunction or exercise limitation is associated with mortality [15]. A recent meta-analysis showed that the most frequent risk factors associated with mortality were FC, heart rate, exercise limitation, pericardial effusion, mPAP, mRAP, CI, stroke volume index, PVR and O2 saturation [21-23]. With the exception of pericardial effusion, we did not find these associations in our study population.

The main limitation of our present work is that it was an observational study with a small number of newly diagnosed cases compared with previously diagnosed cases that were included retrospectively; thus, the possibility of selection bias cannot be avoided. In addition, predictors of survival were limited to baseline demographic and hemodynamic variables because all patients did not have biomarker or 6MWT studies at the time of enrolment.

In conclusion, the survival rate of our $\mathrm{PH}$ patients is higher than reported in previous studies. This increase in survival may be due to improved knowledge, diagnosis, symptom management and adequate vasodilator therapy. Identification of the risk factors associated with mortality remains a significant and uncompleted task. Application of a 
Citation: Reyes LR, Nauffal D, Ortega GA, Menéndez MA, Fandos MJ, et al. (2015) Clinical Characteristics and Survival of Patients with

predictive model may help to reduce the mortality of this severe disease.

\section{References}

1. Galiè N, Hoeper MM, Humbert M (2009) Task Force for Diagnosis and Treatment of Pulmonary Hypertension of European Society of Cardiology (ESC)European Respiratory Society (ERS)International Society of Heart and Lung Transplantation (ISHLT) Guidelines for the diagnosis and treatment of pulmonary hypertension. Eur Respir J 346: 1219-1263.

2. Rubin LJ (1997) Primary pulmonary hypertension. N Engl J Med 336: 111-117.

3. Farber HW, Loscalzo J (2004) Pulmonary arterial hypertension. N Engl J Med 351: 1655-1665.

4. D'Alonzo GE, Barst RJ, Ayres SM, Bergofsky EH, Brundage BH, et al. (1991) Survival in patients with primary pulmonary hypertension. Results from a national prospective registry. Ann Intern Med 115: 343-349.

5. Humbert M, Sitbon O, Yaïci A, Montani D, O'Callaghan DS, et al. (2010) Survival in incident and prevalent cohorts of patients with pulmonary arterial hypertension. Eur Respir J 36: 549-555.

6. Galiè N, Manes A, Negro L, Palazzini M, Bacchi-Reggiani ML, et al. (2009) A meta-analysis of randomized controlled trials in pulmonary arterial hypertension. Eur Heart J 30: 394-403.

7. McLaughlin VV, Shillington A, Rich S (2002) Survival in primary pulmonary hypertension: the impact of epoprostenol therapy. Circulation 106: 1477-1482.

8. Sitbon O, Humbert M, Nunes H, Parent F, Garcia G, et al. (2002) Longterm intravenous epoprostenol infusion in primary pulmonary hypertension: prognostic factors and survival. J Am Coll Cardiol 40: 780-788.

9. Provencher S, Sitbon O, Humbert M, Cabrol S, Jaïs X, et al. (2006) Longterm outcome with first-line bosentan therapy in idiopathic pulmonary arterial hypertension. Eur Heart J 27: 589-595.

10. Humbert M, Sitbon O, Chaouat A, Bertocchi M, Habib G, et al. (2006) Pulmonary arterial hypertension in France: results from a national registry. Am J Respir Crit Care Med 173: 1023-1030.
11. Peacock AJ, Murphy NF, McMurray JJ, Caballero L, Stewart S (2007) An epidemiological study of pulmonary arterial hypertension. Eur Respir J 30: 104-109.

12. Badesch DB, Raskob GE, Elliott CG, Krichman AM, Farber HW, et al. (2010) Pulmonary arterial hypertension: baseline characteristics from the REVEAL Registry. Chest 137: 376-387.

13. Escribano-Subias P, Blanco I, López-Meseguer M, Lopez-Guarch CJ, Roman A, et al. (2012) Survival in pulmonary hypertension in Spain: insights from the Spanish registry. Eur Respir J 40: 596-603.

14. Humbert M, Sitbon O, Yaïci A, Montani D, O'Callaghan DS, et al. (2010) Survival in incident and prevalent cohorts of patients with pulmonary arterial hypertension. Eur Respir J 36: 549-555.

15. Humbert M, Sitbon O, Chaouat A, Bertocchi M, Habib G, et al. (2010) Survival in patients with idiopathic, familial, and anorexigen-associated pulmonary arterial hypertension in the modern management era. Circulation 122: 156-163.

16. Hoeper MM, Mayer E, Simonneau G, Rubin LJ (2006) Chronic thromboembolic pulmonary hypertension. Circulation 113: 2011-2020.

17. Pengo V, Lensing AW, Prins MH, Marchiori A, Davidson BL, et al. (2004) Incidence of chronic thromboembolic pulmonary hypertension after pulmonary embolism. N Engl J Med 350: 2257-2264.

18. Pepke-Zaba J, Delcroix M, Lang I, Mayer E, Jansa P, et al. (2011) Chronic thromboembolic pulmonary hypertension $(\mathrm{CTEPH})$ : results from an international prospective registry. Circulation 124: 1973-1981.

19. Lahm T, Chakinala MM (2013) World Health Organization group 5 pulmonary hypertension. Clin Chest Med 34: 753-778.

20. Fenstad ER, Le RJ, Sinak LJ, Maradit-Kremers H, Ammash NM, et al. (2013) Pericardial effusions in pulmonary arterial hypertension: characteristics, prognosis, and role of drainage. Chest 144: 1530-1538.

21. Swiston JR, Johnson SR, Granton JT (2010) Factors that prognosticate mortality in idiopathic pulmonary arterial hypertension: a systematic review of the literature. Respir Med 104: 1588-1607.

22. Thenappan T, Shah SJ, Rich S, Tian L, Archer SL, et al. (2010) Survival in pulmonary arterial hypertension: a reappraisal of the NIH risk stratification equation. Eur Respir J 35: 1079-1087.

23. Benza RL, Miller DP, Barst RJ, Badesch DB, Frost AE, et al. (2012) An evaluation of long-term survival from time of diagnosis in pulmonary arterial hypertension from the REVEAL Registry. Chest 142: 448-456. 